\title{
Subprodutos de frutas tropicais desidratados por secagem convectiva
}

\section{By-products of tropical fruits dehydrated by convective}

\author{
Viviana Pereira de Meneses ${ }^{* 1}$, José Ramon Afonso da Silva ${ }^{2}$, João Ferreira Neto ${ }^{3}$, Hermano Oliveira Rolim ${ }^{4}$, Ana Luiza \\ Macedo de Araújo ${ }^{5}$, Poliana Sousa Epaminondas Lima ${ }^{6}$
}

\begin{abstract}
Resumo: O Brasil, nos últimos anos, ampliou sua produção agroindustrial, aumentando, consequentemente, a quantidade de resíduos produzidos. Uma alternativa para seu aproveitamento é a transformação destes subprodutos por secagem, já que produtos desidratados têm se destacado pela forma prática de comercialização. Uma forma de empregar esses resíduos após a sua desidratação é a incorporação dos mesmos sob forma de pós, em produtos alimentícios. Diante do exposto, objetivou-se estudar os resíduos desidratados de manga (RDM), de goiaba (RDG) e de acerola (RDA), obtidos por meio de secagem convectiva $\left(55^{\circ} \mathrm{C} / 48 \mathrm{~h}\right)$. Foram avaliadas as características físico-químicas (aw, umidade, sólidos totais, cinzas, acidez total, acidez expressa em ácido cítrico, $\mathrm{pH}$, sólidos solúveis, composição centesimal e valor calórico), colorimétricas, propriedades funcionais e qualidade higiênico-sanitária dos resíduos desidratados. RDM destacou-se em relação ao teor de sólidos solúveis (51,65 ${ }^{\circ}$ Brix). RDG apresentou maiores teores de sólidos totais $(93,91 \%)$, pH $(4,23 \%)$ e lipídios $(7,15 \%)$ em relação aos demais. RDA apresentou maior acidez total (10,79\%), acidez em ácido cítrico $(6,91 \%)$, cinzas $(3,28 \%)$ e proteínas $(15,40 \%)$. RDM e RDG apresentaram maior quantidade de carboidratos presentes, no entanto, RDG contém maior valor calórico (402,91 Kcal). Quanto à análise colorimétrica, RDG apresentou melhor coloração. Em relação às propriedades funcionais, RDA destacou-se quanto aos compostos fenólicos, à atividade antioxidante e à vitamina C, enquanto que RDG destacou-se quanto ao teor de carotenoides. Quanto aos parâmetros microbiológicos, todos os resíduos desidratados atenderam ao determinado pela legislação. Os resíduos de frutas tropicais desidratados podem ser aplicados em produtos alimentícios, pelas suas propriedades funcionais e nutricionais.
\end{abstract}

Palavras-chave: Resíduos; Aproveitamento; Desidratação; Valor nutricional.

\begin{abstract}
Brazil, in recent years, has expanded its agroindustrial production, increasing, consequently, the amount of waste produced. An alternative its utilization is the transformation of these by-products by drying, since dehydrated products have been highlighted by the practical form of commercialization. One way to use these residues after their dehydration is the incorporation of the same ones in the form of powders, in foodstuffs. In view of the above, the objective was to study the dehydrated manure (RDM), guava (RDG) and acerola (RDA) residues obtained by means of convective drying $\left(55^{\circ} \mathrm{C} / 48 \mathrm{~h}\right)$. The physico-chemical characteristics (aw, moisture, total solids, ash, total acidity, acidity expressed as citric acid, pH, soluble solids, centesimal composition and calorific value), colorimetric, functional properties and hygienic-sanitary quality of dehydrated residues. RDM stands out in relation to the soluble solids content $\left(51,65^{\circ} \mathrm{Brix}\right)$. RDG presented higher total solids $(93,91 \%), \mathrm{pH}(4,23 \%)$ and lipids $(7,15 \%)$ in relation to the others. RDA showed higher total acidity $(10,79 \%)$, acidity in citric acid $(6,91 \%)$, ash $(3,28 \%)$ and protein $(15,40 \%)$. RDM and RDG presented higher amount of carbohydrates present, however, RDG contains higher caloric value $(402,91 \mathrm{Kcal})$. Regarding the colorimetric analysis, RDG showed better staining. In relation the functional properties, RDA was highlighted in terms of phenolic compounds, antioxidant activity and vitamin C, while RDG was highlighted in terms of carotenoid content. Regarding microbiological parameters, all dehydrated residues met the requirements of the legislation. Residues of dehydrated tropical fruits can be applied in food products, due to their functional and nutritional properties.
\end{abstract}

Key words: Waste; Recovery; Dehydration; Nutritional value.

\footnotetext{
*Autor para correspondência

Recebido para publicação em 08/06/2018; aprovado em 19/09/2018

${ }^{1}$ Graduada em Tecnologia em Alimentos, Instituto Federal de Educação, Ciência e Tecnologia da Paraíba, Campus Sousa; Fone: (83) 981447788, E-mail: vivianapereira2012@hotmail.com

${ }^{2}$ Graduando em Tecnologia em Alimentos, Instituto Federal de Educação, Ciência e Tecnologia da Paraíba, Campus Sousa; E-mail: ramonafonso016@gmail.com

${ }^{3}$ Mestre em Sistemas Agroindustriais, Instituto Federal de Educação, Ciência e Tecnologia da Paraíba, Campus Sousa; E-mail: j-f-n@ bol.com.br

${ }^{4}$ Doutorando em Agronomia, Instituto Federal de Educação, Ciência e Tecnologia da Paraíba, Campus Sousa; E-mail: rolimano@ hotmail.com

${ }^{5}$ Doutorando em Engenharia Química, Universidade Federal do Rio Grande do Norte, Natal- RN; E-mail: analu.macedoaraujo@gmail.com

${ }^{6}$ Doutora em Ciência e Tecnologia de Alimentos, Instituto Federal de Educação, Ciência e Tecnologia da Paraíba, Campus Sousa; E-mail: polis.epaminondas@yahoo.com.br
} 


\section{INTRODUÇÃO}

O consumo de frutas tropicais tem crescido nos últimos anos, devido às suas características benéficas à saúde. A baixa ocorrência de doenças degenerativas em pessoas que consomem frutas pode estar atrelada ao efeito de substâncias antioxidantes, como os compostos fenólicos (OLIVEIRA, 2014). Além de apresentarem compostos bioativos, frutas como manga, goiaba e acerola são ricas nutricionalmente, além de possuírem sabor agradável e boa aceitação (FARAONI, 2009).

A manga (Mangifera indica L.), originária do sudeste da Índia, possui sabor e valor nutricional apreciável (MATOS, 2000), destacando-se por apresentar alto teor de vitamina A. O processamento dessa fruta acarreta grande geração de resíduos, representados pelas sementes (amêndoa) e cascas, as quais nem sempre recebem destino final adequado, sendo descartadas no meio ambiente, o que caracteriza um desperdício, uma vez que esses resíduos são reconhecidamente ricos em compostos bioativos, promotores de saúde e detentores de importância tecnológica (ARBOS et al., 2013).

O Brasil é o terceiro maior produtor mundial de goiaba (Psidium guajava L.) (PEREIRA, 2009), fruta pertencente à família Myrtaceae, originária da América, sendo de grande destaque nas regiões tropicais e subtropicais, com boa aceitação do consumo in natura, tendo sido aplicada em diversos produtos industrializados como doces, sucos, geleias, entre outros, por possuir importante valor funcional, sensorial e nutritivo (SILVA, 2007; HAIDA et al., 2015). Destaca-se por ser fonte de vitamina $\mathrm{C}$, betacaroteno, licopeno $\mathrm{e}$ compostos fenólicos (FARAONI, 2009). Estima-se que os resíduos resultantes de 10 toneladas do processamento de goiaba são descartados em aterros sanitários ou céu aberto por ano. Esses resíduos poderiam ser aproveitados para alimentação humana, já que apresentam elevado valor nutricional (PEREIRA, 2009).

A acerola (Malpighia emarginata D.C.) é uma fruta tropical com valor econômico e nutricional, por apresentar alto teor de vitamina $\mathrm{C}$, aliado à presença de carotenoides $\mathrm{e}$ antocianinas, sendo, portanto, um alimento com alto potencial funcional. Possui sabor e aroma agradáveis ao paladar, além de apresentar excelente rendimento no aproveitamento industrial, o que possibilita a fabricação de diversos produtos (FREITAS et al., 2006). De forma geral, a polpa da acerola é a parte mais aproveitada pelas indústrias alimentícias, todavia, as cascas e sementes vêm sendo descartadas e desperdiçadas. Esses resíduos, porém, exibem características nutricionais favoráveis, por serem constituídos de fibras, proteínas, lipídeos e compostos bioativos que podem ser aproveitados (LIMA et al., 2016).

Uma alternativa para o aproveitamento dos resíduos do processamento dessas frutas é a sua desidratação para a incorporação em produtos processados, tais como bolos, biscoitos, pão, iogurtes, sorvetes entre outros (SOUZA et al., 2010).

A desidratação, ou secagem, é um método eficaz por estender a vida de prateleira dos alimentos, diminuir volume, peso e, também, reduzir custos durante seu transporte e estocagem, devido à remoção da água contida nos alimentos, quando estes são expostos ao calor sob temperatura controlada, por evaporação, sendo a secagem em estufa um exemplo dessa operação (FELLOWS, 2006). Além disso, a desidratação é importante por proporcionar a concentração dos nutrientes que compõem os alimentos (JORGE, 2014).

Diante disso, buscou-se avaliar os subprodutos oriundos do processamento de manga, goiaba e acerola sob efeito de secagem convectiva, quanto às propriedades funcional, físicoquímica e microbiológica.

\section{MATERIAL E MÉTODOS}

O presente estudo foi realizado, no Instituto Federal de Educação, Ciência e Tecnologia da Paraíba (IFPB)- Campus Sousa. As frutas (manga, goiaba e acerola) foram adquiridas e, em seguida, processadas em despolpadeiras, separando-se a polpa das cascas, bagaço e sementes, para determinar o rendimento. Dos três últimos, foram obtidos os resíduos desidratados, por meio de secagem convectiva em estufa $\left(55^{\circ} \mathrm{C} / 48\right.$ horas). A seguir, esses resíduos foram triturados e peneirados, logo depois, embalados e acondicionados $\left(-18^{\circ} \mathrm{C}\right)$. Vale salientar que os mesmos foram submetidos às análises de caracterização físico-químicas (atividade de água, umidade, sólidos totais, cinzas, $\mathrm{pH}$, sólidos solúveis totais, acidez total titulável, acidez expressa em ácido orgânico, proteínas, lipídios, carboidratos e valor calórico), colorimétricas, avaliação da qualidade higiênico-sanitária, compostos fenólicos, atividade antioxidante, carotenoides e vitamina C. Submeteram-se os dados a análises estatísticas, conforme esquema mostrado na Figura 1.

Figura 1. Etapas para a obtenção dos resíduos desidratados das frutas manga, goiaba e acerola

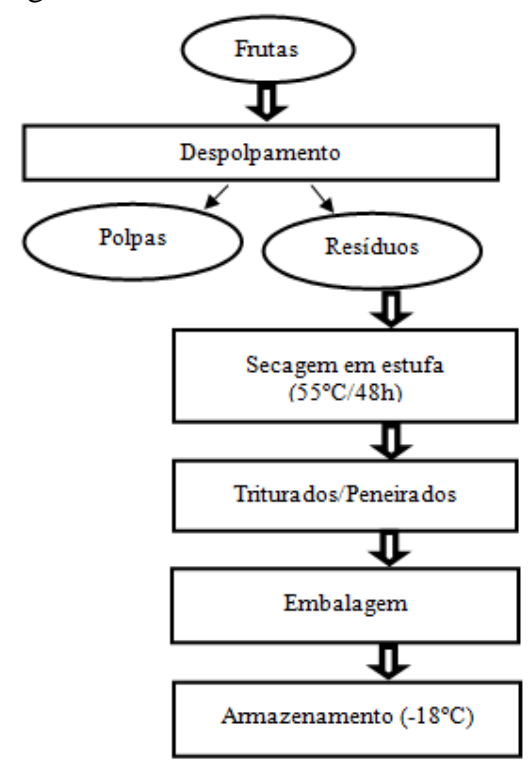

Fonte: Elaboração própria (2018).

\section{Obtenção das matérias primas: frutas e resíduos}

As frutas utilizadas, no presente estudo, foram mangas (Mangifera indica L.), goiabas (Psidium guajava L.) e acerolas (Malpighia emarginata D.C.). As mangas e goiabas foram adquiridas no mercado da cidade de Nazarezinho- PB. As acerolas foram provenientes do próprio Instituto, adquiridas do setor de Agroindústria do IFPB, recepcionadas no Laboratório de Frutas e Hortaliças da Agroindústria e selecionadas de acordo com seu estágio de maturação e qualidade. Após a seleção, passaram pela pesagem inicial e foram lavadas em água corrente, sanitizadas com solução de hipoclorito de sódio (200ppm/15minutos), novamente lavadas 
e despolpadas, utilizando-se equipamento semiautomático, marca Mecval e modelo MC 250. Na sequência, as polpas e os resíduos foram pesados para determinar o rendimento. As polpas e os subprodutos foram embalados e armazenados sob congelamento a $-18^{\circ} \mathrm{C}$, sendo que os resíduos ficaram sob congelamento até a etapa de secagem e obtenção dos resíduos desidratados para a realização das análises. Na Figura 2, estão descritas as etapas do despolpamento das frutas.

Figura 2. Despolpamento das frutas manga, goiaba e acerola

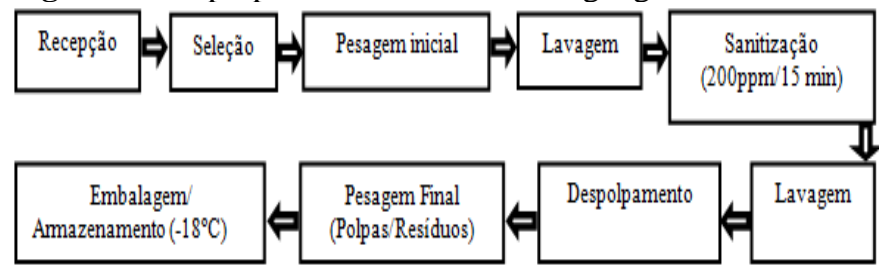

Fonte: Elaboração própria (2018).

\section{Secagem em estufa}

Os resíduos de manga, goiaba e acerola foram colocados sobre as telas de nylon, fixadas em bandejas de alumínio, para facilitar a circulação de ar e a uniformidade da secagem do material. Em seguida, as bandejas foram colocadas na estufa com corrente de ar forçada à temperatura de $55^{\circ} \mathrm{C}$ durante 48 horas (Figura 3), segundo metodologia adaptada de Araújo et al. (2014). Em sequência, os resíduos secos foram triturados pelo processador doméstico Arno, modelo LN30 e peneirados em peneiras de 20 mesh (Figura 4 A) para a obtenção dos resíduos desidratados em forma de pó. Posteriormente, foram acondicionados em recipientes de plásticos polipropileno e mantidos à temperatura de congelamento $\left(-18^{\circ} \mathrm{C}\right)$ (Figura 4$)$.

Figura 3. Secagem dos resíduos de goiabas e acerolas (A) e dos resíduos de manga (B)

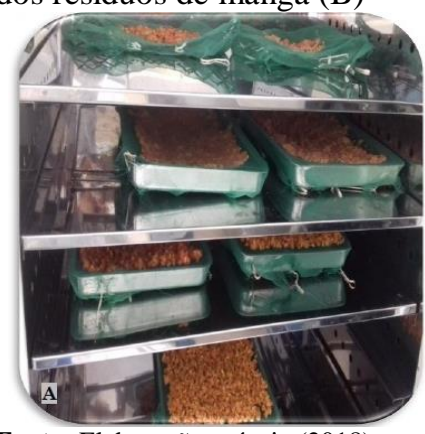

Fonte: Elaboração própria (2018)

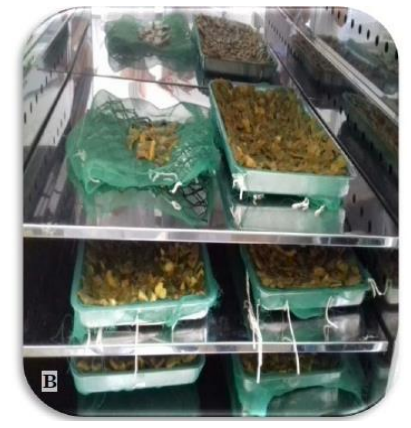

Figura 4. Resíduos desidratados, antes e após a trituração. A: Obtenção do resíduo peneirado; B: Resíduo desidratado de manga (casca); C: Resíduo desidratado de goiaba; D: Resíduo desidratado de acerola; E: Pó de resíduo de manga (casca); F: Pó de resíduo de goiaba e G: Pó de resíduo de acerola
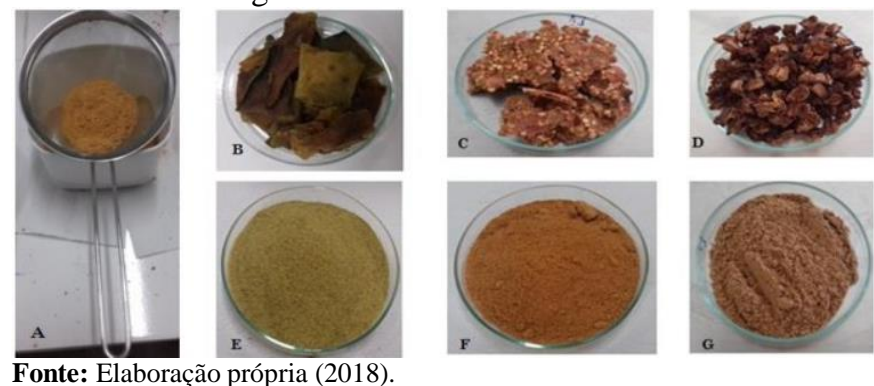

Caracterização físico-química dos resíduos desidratados

As análises físico-químicas dos resíduos desidratados das frutas foram realizadas em triplicata, determinando-se os parâmetros de teor de atividade de água (aw) pelo analisador de atividade de água; umidade, pela estufa com circulação e renovação de ar; sólidos totais, pela diferença da umidade por 100\%; frações de cinzas, utilizando a chapa aquecedora e o formo mufla; $\mathrm{pH}$, pelo método de potenciometria; sólidos solúveis totais, determinado pelo refratômetro portátil; acidez total titulável e acidez expressa em ácido orgânico através do processo de titulação; proteínas, pelo método de Kjeldahl; lipídeos, por Soxhlet; carboidratos, por diferença, e valor calórico, pela utilização dos dados de carboidratos, proteínas e lipídeos. A análise colorimétrica foi realizada no sistema (CIE L*, a*, b*- CIELAB). Todas as análises foram realizadas com base nos métodos analíticos descritos por Instituto Adolfo Lutz (IAL, 2008).

\section{Avaliação da qualidade higiênico-sanitária dos resíduos desidratados}

As análises microbiológicas para os resíduos desidratados seguiram a RDC $\mathrm{n}^{\mathbf{0}} 12$, de 2 de janeiro de 2001, da Agência Nacional de vigilância Sanitária (ANVISA), para frutas secas ou dessecadas, sendo avaliados os microrganismos coliformes a $45^{\circ} \mathrm{C}$ (termotolerantes) e Salmonella ssp (BRASIL, 2001). Adicionalmente, foram analisados coliformes a $35^{\circ} \mathrm{C}$ (totais), além de bolores e leveduras e aeróbios mesófilos.

\section{Determinação das propriedades funcionais dos resíduos das frutas}

A partir dos resíduos das frutas, obtidos por secagem em estufa, foram preparados extratos aquosos para a avaliação dos compostos fenólicos e da capacidade antioxidante. A extração foi feita conforme o procedimento adaptado de Araújo (2014).

A determinação dos compostos fenólicos, para os resíduos desidratados de frutas foi realizada de acordo com a metodologia adaptada de Nóbrega et al. (2014), em triplicatas.

Uma curva de padrão de calibração foi construída com diferentes concentrações de ácido gálico, diluídas com etanol a 95\%. Os resultados foram expressos em miligramas equivalentes de ácido gálico (GAE) por 100 gramas de peso da amostra (mg GAE/100 g amostra) em base úmida (b.u) e base seca (b.s)

A atividade antioxidante dos extratos aquosos dos resíduos desidratados foi determinada utilizando-se 1,1Difenil-2-picrilhidrazil (DPPH) como radical livre. O procedimento experimental foi adaptado da metodologia descrita por Brand-Williams et al. (1995); Duarte-Almeida et al. (2006). A atividade antioxidante foi expressa em porcentagem e os resultados obtidos foram aplicados na Curva padrão preparada com diferentes concentrações de Trolox, sendo o resultado expresso em $\mu \mathrm{mol} \mathrm{TE} / \mathrm{g}$ de amostra.

A análise de carotenoides foi realizada conforme metodologia adaptada de Nagata e Yamashita (1992) e Ambrósio et al. (2006), verificando-se a leitura das amostras em 4 comprimentos de onda diferentes: 663, 645, 505 e 453 $\mathrm{nm}$ em espectrofotômetro.

A determinação de ácido ascórbico para os resíduos desidratados procedeu pelo método de titulação das amostras até aparecer a coloração rósea (BRASIL, 2013). 


\section{RESULTADOS E DISCUSSÃO}

Os rendimentos totais da manga, goiaba e acerola (Tabela 1) foram inferiores a $100 \%$, devido às perdas ocorridas durante o processamento, porém, no processamento da goiaba, houve menor perda, ao comparar-se com o processamento da manga e da acerola.

Tabela 1. Rendimento das polpas, caroços, resíduos úmidos e pós desidratados por secagem convectiva

\begin{tabular}{lccc}
\multicolumn{4}{c}{ Rendimento $(\%)$} \\
\hline \\
\cline { 2 - 4 } Polpas & Manga & Goiaba & Acerola \\
Caroços & 43,81 & 78,00 & 67,79 \\
Resíduos & 18,80 & - & - \\
Pós & 29,56 & 21,58 & 29,18 \\
\hline
\end{tabular}

Observa-se que as frutas goiaba e acerola obtiveram maior rendimento em polpas, superior a $60 \%$, sendo a goiaba mais representativa, enquanto que a manga obteve resultado inferior $(43,81 \%)$, devido à grande quantidade de resíduos correspondendo aos caroços $(18,80 \%)$ e à casca $(29,56 \%)$. Encontraram-se $79 \%$ de polpa, $9,4 \%$ de casca e $11,6 \%$ de semente para a manga tipo Haden, sendo os valores encontrados neste trabalho inferiores para polpa e superiores para resíduos, comparados aos resultados dos referidos autores (DAMIANI et al., 2008).

Obteve-se resultado próximo a $60 \%$ de rendimento em polpa da goiaba madura, sendo o rendimento encontrado, neste trabalho, superior ao dos referidos autores (FREIRE et al., 2009). Apresentou-se, para a polpa da acerola, 73,68\% de rendimento, sendo o resultado desse estudo inferior ao referido pelos autores (CAETANO et al., 2011).
$\mathrm{O}$ processamento das frutas resultou em uma significativa produção de resíduos. Os subprodutos de manga e goiaba apresentaram um melhor rendimento em pó, de $22,68 \%$ e $21,52 \%$, respectivamente, quando comparados com a acerola $(13,85 \%)$. Para o rendimento da farinha de acerola, obtida a $50,0 \pm 2,0^{\circ} \mathrm{C}$, conseguiu-se $12,3 \%$ para o lote 1 , desidratado por 38,4 horas, $12,1 \%$ para o lote 2 , seco durante 36,5 horas, e $12,8 \%$ para o lote 3 , desidratado por 34,0 horas, sendo os resultados deste estudo próximos aos determinados pelo autor (SOBRINHO, 2014).

O rendimento do pó da manga encontrado, neste estudo, foi superior ao encontrado na literatura (REINOSO et al., 2017), visto que obtiveram $16,68 \%$ e $17,09 \%$ de rendimento para a farinha da casca da manga Tommy atkins, seca a $60^{\circ} \mathrm{C}$ e $70^{\circ} \mathrm{C}$, respectivamente.

Encontrou-se 9,94\% de rendimento para resíduo da goiaba liofilizada, sendo que o pó do resíduo da goiaba, obtido neste estudo, apresentou um maior rendimento, diante da desidratação por secagem convectiva, quando comparado aos resultados do referido autor (PRADO, 2009). Isso mostra que a secagem convectiva não interferiu no rendimento dos resíduos.

Nota-se, na Tabela 2, que os resíduos in natura de manga, goiaba e acerola apresentaram elevado teor de umidade $(84,70 \%, 75,01 \%$ e $81,99 \%$, respectivamente) e de atividade de água $(0,985 ; 0,902$ e 0,971 , respectivamente), sendo que o subproduto da manga e acerola obtiveram valores semelhantes para esses parâmetros e também para sólidos totais $(\mathrm{p}>0,05)$. Verifica-se, ainda, que quanto maior a quantidade de água presente nos resíduos, seja na forma in natura ou de pó, menor será o teor de sólidos totais contidos.

Tabela 2. Atividade de água, umidade e extrato seco dos resíduos in natura das frutas manga, goiaba e acerola

\begin{tabular}{lccc}
\hline \multicolumn{2}{c}{ Determinações } & \multicolumn{3}{c}{ Resíduos } & RIA \\
\hline Atividade de água (\%) & RIM & RIG & $0,971 \pm 0,00^{\mathrm{a}}$ \\
Umidade (\%) & $0,985 \pm 0,00^{\mathrm{a}}$ & $0,902 \pm 0,00^{\mathrm{b}}$ & $81,99 \pm 0,87^{\mathrm{a}}$ \\
Sólidos Totais (\%) & $84,70 \pm 0,87^{\mathrm{a}}$ & $75,01 \pm 1,60^{\mathrm{b}}$ & $18,01 \pm 0,87^{\mathrm{b}}$ \\
\hline
\end{tabular}

Médias seguidas por diferentes letras minúsculas na mesma linha diferem estatisticamente (p<0,05), pelo Teste de Tukey. RIM= Resíduo in natura de manga (casca); RIG= Resíduo in natura de goiaba e RIA= Resíduo in natura de acerola.

Observa-se que o teor de umidade, após o processo de desidratação, foi reduzido para 13,42 \% (RDM), 6,09\% (RDG) $11,31 \%$ (RDA) assim como a atividade de água foi diminuída para 0,391 (RDM), 0,301 (RDG) e 0,378 (RDA). Neste componente, o resíduo desidratado da manga não apresentou diferença estatística $(\mathrm{p}>0,05)$ para o resíduo desidratado da acerola para as variáveis atividade de água, umidade e sólidos totais. Isso permite inferir que quanto menor o teor de umidade e atividade de água do resíduo obtido após o processamento da fruta, melhores serão a qualidade do alimento e estabilidade microbiológica dos resíduos desidratados, como verificado no RDG, que apresentou maior concentração de sólidos totais (Tabela 3).

Não existe uma legislação que determine a porcentagem de água presente em resíduos de frutas desidratadas, mas a RDC no 272 de 2005 da Agência Nacional de Vigilância Sanitária- ANVISA (BRASIL, 2005) determina a umidade máxima de $25 \%$ para frutas secas e desidratadas. Portanto, os resíduos estão dentro do limite estabelecido para frutas secas (BRASIL, 2005), denotando a adequação da temperatura e do tempo utilizados na secagem para atender à legislação pertinente.
Os alimentos podem ser ordenados em três grupos (RIBEIRO; SERAVALLI, 2007), de acordo com sua atividade de água (aw): umidade baixa (aw até 0,6 ), umidade intermediária (aw entre 0,6 e 0,9 ) e umidade elevada (aw acima de 0,9). Com base nesses grupos, os subprodutos desidratados, obtidos a partir dos resíduos da manga, goiaba e acerola estão inseridos na classificação de baixa atividade de água, o que é bom, pois quanto menor a água livre, menos umidade estará disponível para o crescimento de microrganismos (GAVA et al., 2008).

Os resíduos desidratados da manga e da acerola são estatisticamente semelhantes $(p>0,05)$ quanto aos sólidos totais (ST), com teores de 86,58 e $88,69 \%$, respectivamente. No entanto, são significativamente inferiores ao resíduo desidratado da goiaba, que apresentou 93,91\% para este parâmetro (Tabela 3). Resultados semelhantes foram encontrados para o subproduto da acerola com $85,07 \%$, mas inferiores aos resíduos da goiaba com $86,33 \%$ (JÚNIOR et al., 2006). O valor da matéria seca do resíduo desidratado de manga foi semelhante ao da literatura (DUARTE et al., 2006), os quais obtiveram na análise $88,46 \%$ de matéria seca para manga passa. 
Subprodutos de frutas tropicais desidratados por secagem convectiva

Tabela 3. Resultados das análises dos resíduos desidratados a $55^{\circ} \mathrm{C}$ de manga, goiaba e acerola

$$
\text { Determinações }
$$
Resíduos desidratados

Atividade de água $(\%)$

Umidade $(\%)$

Sólidos Totais $(\%)$

Acidez Total Titulável (\%)

Acidez expressa em AC* $(\%)$

$\mathrm{pH}$

Sólidos Solúveis Totais $\left({ }^{\circ}\right.$ Brix $)$

RDM
$0,391 \pm 0,02^{\mathrm{a}}$
$13,42 \pm 1,59^{\mathrm{a}}$
$86,58 \pm 1,59^{\mathrm{b}}$
$7,46 \pm 0,44^{\mathrm{b}}$
$4,77 \pm 0,28^{\mathrm{b}}$
$3,93 \pm 0,05^{\mathrm{b}}$
$51,65 \pm 0,01^{\mathrm{a}}$

RDG
$0,301 \pm 0,00^{\mathrm{b}}$
$6,09 \pm 1,02^{\mathrm{b}}$
$93,91 \pm 1,02^{\mathrm{a}}$
$3,22 \pm 0,28^{\mathrm{c}}$
$2,06 \pm 0,18^{\mathrm{c}}$
$4,23 \pm 0,11^{\mathrm{a}}$
$29,73 \pm 0,06^{\mathrm{c}}$

RDA

$0,378 \pm 0,00^{\mathrm{a}}$

$11,31 \pm 1,05^{\mathrm{a}}$

$88,69 \pm 1,05^{\mathrm{b}}$

$10,79 \pm 0,17^{\mathrm{a}}$

$6,91 \pm 0,11^{\mathrm{a}}$

$3,46 \pm 0,01^{\mathrm{c}}$

$40,79 \pm 0,05^{\mathrm{b}}$

Médias seguidas por diferentes letras minúsculas na mesma linha diferem estatisticamente $(\mathrm{p}<0,05)$, pelo Teste de Tukey. RDM= Resíduo desidratado de manga (casca); RDG= Resíduo desidratado de goiaba e RDA= Resíduo desidratado de acerola. *Ácido cítrico.

Em relação à acidez, observa-se que houve diferença estatística $(\mathrm{p}<0,05)$ entre RDM, RDG e RDA, destacando-se o resíduo desidratado da acerola, que apresentou acidez total titulável mais elevada (10,79\%), assim como a acidez em ácido cítrico $(6,91 \%)$. Em relação a esses valores, obtive-se percentual de $25,02 \%$ para acidez total titulável da farinha de resíduos de acerola (SILVA et al., 2012), acidez mais elevada do que o presente estudo, enquanto que para acidez em ácido cítrico, encontrou-se 3,21\% para o resíduo da polpa de acerola seco a $55^{\circ} \mathrm{C}$ em estufa de circulação de ar (NUNES et al., 2015), sendo o valor encontrado no presente estudo superior.

O resíduo desidratado da goiaba foi o que resultou em menor acidez total titulável $(3,22 \%)$ e acidez expressa em ácido cítrico $(2,06 \%)$, resultado semelhante ao encontrado na literatura (MUNIZ et al., 2016), para a acidez total em resíduos secos da goiaba $(2,86 \%$ a $3,43 \%)$ a $55^{\circ} \mathrm{C}$, durante 240 dias de armazenamento.

O resíduo da casca da manga apresentou valor de acidez superior ao da goiaba e inferior ao da acerola para acidez total titulável e acidez em ácido cítrico, correspondendo a 7,46\% e $4,77 \%$, respectivamente (Tabela 3 ). Obteve-se, para a farinha da casca da manga, acidez total titulável de 2,3\%, sendo o valor encontrado, neste estudo, superior ao descrito pelos autores (NOBRE et al., 2011). Encontrou-se, para a farinha da casca de manga, $0,78 \%$ de acidez em ácido cítrico (MORENO, 2016), valor menor do que o observado no presente estudo.

Os resíduos desidratados, de maneira geral, apresentaram uma acidez aceitável, sendo que os produtos que contêm mais ácido são naturalmente mais estáveis em relação à deterioração (BEZERRA, 2009). A acidez expressa em ácido cítrico foi mais alta na presente pesquisa, ao comparar-se com os resíduos secos da literatura, podendo isso ser atribuído ao processo de secagem pelo qual os resíduos passaram, que pode ter contribuído para a concentração dos ácidos orgânicos (AQUINO et al., 2010).
Observa-se que os valores de $\mathrm{pH}$ apresentaram diferença estatística $(\mathrm{p}<0,05)$ para todos os resíduos desidratados estudados (3,93, para RDM; 4,23, para RDG e 3,46, para RDA), resultados semelhantes aos obtidos para os resíduos desidratados de goiaba $(4,04)$ e acerola $(3,72)$, e inferior ao da manga $(5,36)$ (OLIVEIRA, 2014). É desejável um pH inferior a 4,5 pois é importante para conservar e preservar as características do alimento, dificultando a proliferação de microrganismos (MUNIZ et al., 2016). Como se pode verificar, todos os resíduos desidratados obtiveram valores abaixo desse limite, o que é importante na qualidade do produto final.

Os resultados dos sólidos solúveis totais de todas as amostras secas foram significativamente diferentes $(p<0,05)$. O teor de sólidos solúveis foi maior para o resíduo de manga (51,65 ${ }^{\circ}$ Brix) ao comparar-se com RDG $\left(29,73^{\circ}\right.$ Brix $)$ e RDA (40,79 ${ }^{\circ}$ Brix) (Tabela 3). Os resultados encontrados, neste estudo, foram superiores aos determinados pela literatura (OLIVEIRA, 2014), para o resíduo da manga (25,30 ${ }^{\circ}$ Brix), podendo tal fato ser explicado pela baixa temperatura empregada $\left(37^{\circ} \mathrm{C} / 24\right.$ horas) pelos autores, que contribuiu para baixa concentração de sólidos solúveis. O resíduo desidratado da goiaba apresentou menor teor de sólidos solúveis totais (29,73 ${ }^{\circ}$ Brix), comparando-se com os demais resíduos, sendo este resultado superior ao descrito na literatura (OLIVEIRA, 2014) $\left(10,63{ }^{\circ}\right.$ Brix $)$. O resíduo de acerola apresentou sólidos solúveis totais de $40,79^{\circ}$ Brix, sendo esse valor próximo que o descrito na literatura (AQUINO et al., 2010), que descreveu um teor de $47,50{ }^{\circ}$ Brix na farinha do resíduo da acerola, desidratado a $60^{\circ} \mathrm{C}$.

Quanto ao teor de cinzas (Tabela 4), o resíduo desidratado de acerola apresentou, neste estudo, maior concentração de minerais em relação aos demais. Obteve-se um teor de cinzas de 3,02\% para a farinha da casca da manga Tommy atkins, sendo o valor obtido, neste trabalho, para resíduo desidratado da manga $(2,95 \%)$ compatível com o encontrado pelos autores (MEIRELES; SOUZA, 2015).

Tabela 4. Caracterização físico-química dos resíduos desidratados de manga, goiaba e acerola

\begin{tabular}{lccc}
\hline \multicolumn{1}{c}{ Parâmetros } & RDM & RDG & RDA \\
\hline Umidade (\%) & $13,42 \pm 1,59^{\mathrm{a}}$ & $6,09 \pm 1,02^{\mathrm{b}}$ & $11,31 \pm 1,05^{\mathrm{a}}$ \\
Cinzas (\%) & $2,95 \pm 0,03^{\mathrm{b}}$ & $2,12 \pm 0,03^{\mathrm{c}}$ & $3,28 \pm 0,04^{\mathrm{a}}$ \\
Proteínas (\%) & $7,06 \pm 0,10^{\mathrm{c}}$ & $10,91 \pm 0,83^{\mathrm{b}}$ & $15,40 \pm 0,49^{\mathrm{a}}$ \\
Lipídios (\%) & $1,61 \pm 0,14^{\mathrm{c}}$ & $7,15 \pm 0,54^{\mathrm{a}}$ & $3,84 \pm 0,25^{\mathrm{b}}$ \\
Carboidratos (\%)* & $74,96 \pm 1,54^{\mathrm{a}}$ & $73,73 \pm 1,86^{\mathrm{a}}$ & $66,17 \pm 1,51^{\mathrm{b}}$ \\
Valor Calórico (Kcal) & $342,57 \pm 1,95^{\mathrm{c}}$ & $402,91 \pm 1,90^{\mathrm{a}}$ & $360,84 \pm 1,62^{\mathrm{b}}$ \\
\hline
\end{tabular}

Médias seguidas por diferentes letras minúsculas na mesma linha diferem estatisticamente ( $<<0,05)$, pelo Teste de Tukey. RDM= Resíduo desidratado de manga (casca); RDG= Resíduo desidratado de goiaba e RDA= Resíduo desidratado de acerola. * Carboidratos por diferença, incluindo fibras.

O resíduo seco da goiaba obteve $2,12 \%$ de cinzas, valor semelhante ao reportado na literatura, que encontrou, para o resíduo da goiaba, o valor de $2,65 \%$ de cinzas (SILVA et al., 2016). O subproduto desidratado da acerola, nesta pesquisa, 
apresentou 3,28\% de cinzas, valor mais elevado do que o determinado na literatura, em que se verificou $2,35 \%$ e $1,99 \%$ de cinzas no resíduo seco a $60^{\circ} \mathrm{C}$ e $70^{\circ} \mathrm{C}$, respectivamente (SILVA, 2017). As principais fontes de minerais são encontradas nas frutas e vegetais, e, como pode ser observado a partir dos resultados desta pesquisa, os resíduos das frutas também contêm quantidades significativas desse constituinte (MEIRELES; SOUZA, 2015).

Observou-se que o resíduo da acerola $(15,40 \%)$ se destacou pelo maior teor proteico em relação ao de manga e goiaba (Tabela 4), sendo esse resultado superior ao encontrado na literatura (BORGES, 2011), para o bagaço da acerola $(9,45 \%)$, seco em leito de jorro. O resíduo desidratado da goiaba $(10,91 \%)$ foi o que apresentou o segundo maior teor de proteínas, resultado acima do encontrado (SOUSA, 2009), em que se obteve $8,81 \%$ para o resíduo da goiaba desidratado a $80^{\circ} \mathrm{C}$ por 4 horas. $\mathrm{O}$ resíduo desidratado de manga $(7,06 \%)$ apresentou menor teor de proteína, quando confrontado com os outros resíduos (Tabela 4). Não obstante, esse teor é cerca de três vezes mais elevado que o reportado em estudo (SANTOS, 2013), que obteve 2,12\% de teor proteico para a farinha da casca de manga Tommy atkins. Em geral, observa-se que os resíduos utilizados, nesta pesquisa, têm alto teor proteico em relação aos dados comparados da literatura. A composição química do material estudado depende da variedade, cultura e estádio de maturação da fruta (SANTOS, 2003).

Para o teor de lipídios, observou-se que o resíduo da goiaba $(7,15 \%)$ apresentou maior concentração lipídica (Tabela 4), semelhantemente ao resultado do estudo (SOUSA, 2009), com 7,99\% de lipídios para o bagaço desidratado da goiaba. Esse valor elevado é devido à maior presença das sementes no resíduo dessa fruta, as quais apresentam alto teor de lipídeos e, quando desidratadas, há uma maior concentração desse componente. $\mathrm{O}$ resíduo desidratado da manga $(1,61 \%)$ apresentou menor teor de lipídio, resultado semelhante ao da literatura (NOBRE et al., 2011), em que se encontrou $1,3 \%$ de lipídios na farinha da casca de manga. $\mathrm{O}$ teor de lipídios detectado no resíduo da acerola foi de 3,84\%, valor semelhante ao obtido em estudo (AGUIAR et al., 2010), em que se encontrou $3,92 \%$ de lipídios para a farinha desidratada de sementes da acerola, a $55 \pm 5^{\circ} \mathrm{C}$.

Em relação aos carboidratos, os resíduos desidratados de manga e goiaba não apresentaram diferença estatística
( $p>0,05)$, porém para o valor calórico não obteve semelhança $(\mathrm{p}<0,05)$. RDG apresentou maior valor calórico. Encontrouse, na caracterização bromatológica do farelo de sementes e casca de manga da variedade Var. Ubá, 81,92\% de carboidratos totais, valor mais elevado do que o presente estudo, com 74,96\%, possivelmente devido à amostra da autora conter o caroço na composição e o resíduo ser uma variedade de fruta diferente (VIEIRA, 2007). Encontrou-se 379,03 de Kcal para a farinha da casca da manga (OLIVEIRA, 2013), valor próximo ao deste estudo, com 342,57 Kcal.

Obteve-se, para o resíduo desidratado da goiaba a $55^{\circ} \mathrm{C}$, $29,52 \%$ e acerola, $70,83 \%$ de carboidratos (ABUD; NARAIN, 2009). Em relação ao valor calórico, encontraram-se, para os resíduos desidratados da goiaba, o valor $266,65 \mathrm{Kcal}$, e para os resíduos desidratados da acerola, 332,53 Kcal. O resíduo desidratado de acerola está próximo dos valores obtidos pelas autoras, enquanto o resíduo da goiaba desidratado encontra-se inferior.

Os resíduos in natura apresentaram diferença estatística $(\mathrm{p}<0,05)$ quanto à cor (Tabela 5), sendo que o subproduto da goiaba e da acerola exibiram um maior valor para o parâmetro L, o que indica uma coloração mais clara do que o resíduo da manga. Em relação ao a*, observa-se, para todos os resíduos, uma coloração vermelha, sendo a tonalidade mais forte para o resíduo de acerola, seguido do resíduo de goiaba. Para o índice $\mathrm{b}^{*}$, que designou o tom amarelo, observou-se maiores índices para o resíduo de acerola, seguida do resíduo de manga e, com menor tendência ao amarelo, o resíduo de goiaba. Assim, dentre os resíduos in natura, o resíduo de acerola destacou-se por apresentar-se mais claro, com tendência à tonalidade vermelha e amarela, compatíveis com as altas concentrações de pigmentos carotenoides, tais como licopeno (vermelho) e $\beta$-caroteno (amarelo) (NÓBREGA, 2012).

O resíduo desidratado da goiaba (Tabela 6), apresentou resultado superior aos dos demais resíduos desidratados para todos os parâmetros $\mathrm{L}^{*}, \mathrm{a}^{*}$ e b*, mostrando-se mais claro, mais vermelho e mais amarelo que as demais amostras. Os resíduos desidratados da manga e da acerola apresentaram semelhanças $(p>0,05)$ para os parâmetros de cor $L^{*}$ e b*, demonstrando diferença estatística $(\mathrm{p}<0,05)$ em relação à coordenada $a^{*}$.

Tabela 5. Parâmetros colorimétricos dos resíduos in natura de manga, goiaba e acerola - L* (luminosidade), a* (teor de vermelho-verde) e b* (coordenada amarelo-azul)

\begin{tabular}{lccc}
\hline Amostras & \multicolumn{3}{c}{ Coordenadas } \\
\hline RIM & L $^{*}$ & $\mathrm{a}^{*}$ & $\mathrm{~b}^{*}$ \\
RIG & $70,05 \pm 0,02^{\mathrm{b}}$ & $2,14 \pm 0,01^{\mathrm{c}}$ & $44,84 \pm 0,18^{\mathrm{b}}$ \\
RIA & $72,50 \pm 0,54^{\mathrm{a}}$ & $28,76 \pm 0,18^{\mathrm{b}}$ & $23,94 \pm 0,75^{\mathrm{c}}$ \\
\hline
\end{tabular}

Médias seguidas da mesma letra na coluna, não diferem entre si (p>0,05), pelo teste de Tukey. RIM= Resíduo in natura de manga (casca); RIG= Resíduo in natura de goiaba e RIA= Resíduo in natura de acerola.

Tabela 6. Parâmetros colorimétricos dos resíduos desidratados de manga, goiaba e acerola - L* (luminosidade), a* (teor de vermelho-verde) e b* (coordenada amarelo-azul)

\begin{tabular}{lccc}
\hline Amostras & \multicolumn{3}{c}{ Coordenadas } \\
\hline RDM & L $^{*}$ & $\mathrm{a}^{*}$ & $\mathrm{~b}^{*}$ \\
RDG & $58,98 \pm 0,09^{\mathrm{b}}$ & $7,18 \pm 0,14^{\mathrm{c}}$ & $22,18 \pm 0,75^{\mathrm{b}}$ \\
RDA & $69,88 \pm 0,00^{\mathrm{a}}$ & $21,28 \pm 0,00^{\mathrm{a}}$ & $34,37 \pm 0,00^{\mathrm{a}}$ \\
\hline
\end{tabular}

Médias seguidas por diferentes letras minúsculas na mesma coluna diferem estatisticamente (p<0,05), pelo Teste de Tukey. RDM= Resíduo desidratado de manga (casca); RDG= Resíduo desidratado de goiaba e RDA= Resíduo desidratado de acerola. 
Ao comparar os resíduos in natura (Tabela 5) com os resíduos desidratados (Tabela 6), verificou-se que o processo de secagem ocasionou o escurecimento das amostras, observado pela redução dos valores da coordenada $\mathrm{L}^{*}$, para todos os grupos estudados. A descoloração do produto final pode ocorrer, em virtude dos impactos ocasionados pela secagem convectiva e pela temperatura empregada, tornandose o alimento mais escuro (VEGA-GALVEZ et al., 2009). Verificou-se a intensificação significativa do índice a* apenas de RIM para RDM, indicando o aumento do tom vermelho diante da secagem dos resíduos de manga, enquanto que, para os resíduos das demais frutas, houve redução desse índice com a secagem. Para o índice b*, observou-se a intensificação da cor amarela com o processo de secagem apenas para os resíduos de goiaba. Essa intensificação ocorreu possivelmente por a secagem não ter influenciado na perda de compostos coloridos, tais como os pigmentos, nos resultados dos índices $a^{*}$ (RDM) e b* (RDG) (NÓBREGA, 2012; ARAÚJO, 2014).

Ao estudar a manga in natura após a secagem convectiva, obteve-se $\mathrm{L}^{*}(52,64), \mathrm{a}^{*}(21,77)$ e $\mathrm{b}^{*}(58,02)$, sendo o resíduo de manga obtido, no presente estudo, mais claro, menos vermelho e menos amarelo que o material estudado pelos autores, provavelmente em virtude da maior

temperatura empregada $\left(60^{\circ} \mathrm{C}\right)$ e da variedade da manga Tommy atkins (MARTIM, 2006). Avaliando-se três lotes de resíduos de acerola desidratados em estufa $\left(50^{\circ} \mathrm{C}\right)$, encontrou para L* $(50,53),(59,10)$ e $(58,32)$; a* $(9,39),(9,26)$ e $(9,35)$ e $b^{*}(19,21),(17,42)$ e $(18,05)$, respectivamente, observando-se que os resultados, desta pesquisa, foram semelhantes apenas para a coordenada $\mathrm{L}^{*}$, em relação aos resultados do autor (SOBRINHO, 2014). Encontrou-se para a goiaba in natura, as tonalidades $\mathrm{L}^{*}=38,60 ; \mathrm{a}^{*}=17,63 \mathrm{e} \mathrm{b}^{*}=20,02$, sendo os valores, do presente estudo superiores aos retratados pelo autor (CRUZ, 2013).

De acordo com os resultados obtidos (Tabela 7), observase que os resíduos da manga (casca), goiaba e acerola, desidratados por secagem em estufa a $55^{\circ} \mathrm{C}$, durante 48 horas, obedecem aos padrões microbiológicos descritos na legislação $\mathrm{n}^{\circ} 12$ de 02 de janeiro de 2001, da ANVISA para frutas desidratadas e secas (BRASIL, 2001). Verifica-se que, além dos microrganismos determinados na legislação para esse grupo alimentício, foram pesquisados outros microrganismos, estando os resíduos desidratados das frutas livres de contaminação para todos os parâmetros microbiológicos avaliados.

Tabela 7. Microbiologia dos resíduos desidratados de manga, goiaba e acerola

\begin{tabular}{|c|c|c|c|c|}
\hline \multicolumn{5}{|c|}{ Resultados } \\
\hline Microrganismos & RDM & RDG & RDA & $\begin{array}{l}\text { Padrões } \\
\text { Microbiológicos* }\end{array}$ \\
\hline Aeróbios Mesófilos (UFC/g) & $\begin{array}{l}<1 \times 10^{1} \\
\text { (est.) }\end{array}$ & $\begin{array}{l}<1 \times 10^{1} \\
\text { (est.) }\end{array}$ & $\begin{array}{l}<1 \times 10^{1} \\
\text { (est.) }\end{array}$ & - \\
\hline Bolores e Leveduras (UFC/g) & $\begin{array}{l}<1 \times 10^{2} \\
\text { (est.) }\end{array}$ & $\begin{array}{l}<1 \times 10^{2} \\
\text { (est.) }\end{array}$ & $\begin{array}{l}<1 \times 10^{2} \\
\text { (est.) }\end{array}$ & - \\
\hline Coliformes à $35^{\circ} \mathrm{C}(\mathrm{NMP} / \mathrm{g})$ & $<3,0$ & $<3,0$ & $<3,0$ & - \\
\hline Coliformes à $45^{\circ} \mathrm{C}(\mathrm{NMP} / \mathrm{g})$ & $<3,0$ & $<3,0$ & $<3,0$ & Máximo $10^{2}$ \\
\hline Staphylococcus coagulase positiva & $<1 \times 10^{2}$ & $<1 \times 10^{2}$ & $<1 \times 10^{2}$ & \\
\hline (UFC/g) & (est.) & (est.) & (est.) & - \\
\hline Salmonella spp. & Ausente & Ausente & Ausente & Ausente \\
\hline
\end{tabular}

RDM= Resíduo desidratado de manga (casca); RDG= Resíduo desidratado de goiaba e RDA= Resíduo desidratado de acerola. * RDC ${ }^{\circ}{ }^{12}$, de 02 de janeiro de 2001, da ANVISA para frutas secas e desidratadas. Est= Estimativa.

Os resíduos das frutas apresentaram quantidades significativas de compostos fenólicos (Tabela 8), diferenciando-se estatisticamente $(\mathrm{p}<0,05)$, sendo o resíduo da acerola o que obteve valores mais expressivos desses compostos, seguido do resíduo de manga e de goiaba, diferentemente dos resultados obtidos na literatura (ARAÚJO et al., 2014), para coprodutos desidratados a $45^{\circ} \mathrm{C}$, com maior teor de compostos fenólicos para resíduos de manga (485,93 mg GAE/100 g), seguidos dos resíduos de acerola (270,68 mg GAE/100g) e de goiaba $(188,44 \mathrm{mg}$ GAE/100 g). Os compostos fenólicos totais podem ser influenciados por diversos fatores, entre eles, origem, colheita, maturação, espécie, armazenamento, crescimento, cultivo, processo de extração e solvente utilizado (KIM et al., 2003; BORGES, 2011).

Tabela 8. Determinações dos compostos bioativos nos resíduos desidratados de manga, goiaba e acerola

\begin{tabular}{lccc}
\hline Determinações & \multicolumn{1}{c}{ Amostras } \\
\hline & RDM & RDG & RDA \\
\cline { 2 - 4 } Fenólicos (mg GAE/100g) b. u & $285,09 \pm 0,81^{\mathrm{b}}$ & $96,80 \pm 0,70^{\mathrm{c}}$ & $377,43 \pm 0,35^{\mathrm{a}}$ \\
Fenólicos (mg GAE/100g) b.s & $332,42 \pm 0,94^{\mathrm{b}}$ & $103,73 \pm 0,79^{\mathrm{c}}$ & $425,56 \pm 0,40^{\mathrm{a}}$ \\
ATA $(\mu$ mol TE/g) b. u & $13,38 \pm 0,13^{\mathrm{b}}$ & $14,62 \pm 0,17^{\mathrm{a}}$ & $14,48 \pm 0,10^{\mathrm{a}}$ \\
ATA $(\mu$ mol TE/g) b. s & $15,60 \pm 0,15^{\mathrm{b}}$ & $15,66 \pm 0,19^{\mathrm{b}}$ & $16,33 \pm 0,11^{\mathrm{a}}$ \\
Carot. (licopeno $\mu \mathrm{g} / 100 \mathrm{~g})$ & $68,39 \pm 0,70^{\mathrm{b}}$ & $427,23 \pm 1,00^{\mathrm{a}}$ & $41,46 \pm 0,86^{\mathrm{c}}$ \\
Carot. $(\beta$-caroteno $\mu \mathrm{g} / 100 \mathrm{~g})$ & $225,35 \pm 0,85^{\mathrm{b}}$ & $333,03 \pm 0,98^{\mathrm{a}}$ & $215,97 \pm 0,98^{\mathrm{b}}$ \\
AAS $(\mathrm{mg} / 100 \mathrm{~g})$ b. u & $224,94 \pm 1,07^{\mathrm{b}}$ & $64,72 \pm 0,02^{\mathrm{c}}$ & $2484,07 \pm 1,00^{\mathrm{a}}$ \\
AAS $(\mathrm{mg} / 100 \mathrm{~g})$ b. $\mathrm{s}$ & $262,29 \pm 1,04^{\mathrm{b}}$ & $69,35 \pm 0,02^{\mathrm{c}}$ & $2800,85 \pm 1,00^{\mathrm{a}}$ \\
\hline LA
\end{tabular}

Letras diferentes sobrescrito na mesma linha indicam diferença significativa $(\mathrm{p}<0,05)$ pelo Teste de Tukey. RDM= Resíduo desidratado de manga (casca); RDG= Resíduo desidratado de goiaba e RDA= Resíduo desidratado de acerola. GAE: Ácido Gálico Equivalente; b.u.: Base úmida; b.s.: Base seca; ATA:

Atividade antioxidante (método do DPPH.); TE: Trolox; Carot: Carotenoides e AAS: Ácido ascórbico. 
No que se refere à capacidade antioxidante, para os resíduos de frutas, observou-se que não houve diferença estatística $(p>0,05)$ entre RDG e RDA, com os resultados expressos em base úmida, apresentando resultados mais elevados do que o RDM. Entretanto, para os resultados determinados em base seca, o resíduo da acerola apresentou maior atividade antioxidante, quando comparado aos demais resíduos. Encontrou-se, para o resíduo de manga (bagaço da polpa) liofilizado, o valor de 33,03 $\mu \mathrm{mol} \mathrm{TE} / \mathrm{g}$ em matéria seca (INFANTE et al., 2013), apresentando, o presente estudo, resultado inferior ao dos referidos autores, provavelmente, devido ao diferente processo de secagem e ao resíduo do presente estudo considerar somente a casca da manga.

O resíduo da goiaba, no presente estudo, apresentou maior atividade antioxidante em relação ao demonstrado na literatura (MORAES et al., 2014), em que se encontrou o valor de 9,06 $\mu \mathrm{mol} \mathrm{TE} / \mathrm{g}$ (base úmida) de atividade antioxidante no resíduo de goiaba vermelha desidratado em secador de bandejas $\left(70^{\circ} \mathrm{C}\right.$ por 510 minutos). Possivelmente, a combinação de tempo e temperatura utilizada no processo de secagem, para essa pesquisa $\left(55^{\circ} \mathrm{C} / 48 \mathrm{~h}\right)$, tenha contribuído para a maior preservação de compostos com atividade antioxidante. Temperaturas e velocidades de secagem mais baixas reduzem a perda da atividade antioxidante e compostos bioativos (CRUZ et al., 2014).

Ao estudar a atividade antioxidante dos extratos aquosos do bagaço da goiaba vermelha liofilizado, encontrou-se 16,28 $\mu \mathrm{mol} \mathrm{TE} / \mathrm{g}$ de amostra (MELO, 2010), sendo o valor obtido, neste trabalho, próximo ao descrito pelo autor.

Os dados referentes aos teores de carotenoides, expressos em licopeno e $\beta$-caroteno, presentes nos resíduos, apresentaram diferença estatística $(\mathrm{p}<0,05)$ entre as amostras analisadas, sendo o resíduo da goiaba o de maior destaque para esses dois carotenoides, seguida do resíduo da manga e da acerola, semelhantes estatisticamente $(p>0,05)$ para $\beta$ caroteno.

Ao quantificar o teor de $\beta$-caroteno no resíduo de goiaba, obtido na extração por Soxhlet em diferentes condições, encontrou-se, empregando na extração hexano, diclorometano e metanol, no resíduo liofilizado, os valores de $270,7 \mu \mathrm{g} / 100 \mathrm{~g}, \quad 494,9 \mu \mathrm{g} / 100 \mathrm{~g} \quad$ e $228,3 \mu \mathrm{g} / 100 \mathrm{~g}$, respectivamente (SANTOS, 2013). O teor de $\beta$-caroteno no resíduo desidratado de goiaba $(333,03 \mu \mathrm{g} / 100 \mathrm{~g})$, no presente estudo, considerando-se que a extração foi realizada utilizando-se uma mistura de éter de petróleo e acetona, foi superior aos resultados referidos pela autora, para o extrato de hexano e de metanol, e inferior ao extrato de diclorometano, demonstrando que o método e o solvente utilizados para extração influenciam consideravelmente os resultados da análise.

Todos os resíduos exibiram considerável teor de ácido ascórbico, com destaque para o resíduo da acerola, que apresentou concentração superior em relação aos demais $(\mathrm{p}<0,05)$, seguido pelos resíduos da manga e da goiaba.

O teor de ácido ascórbico do resíduo desidratado da acerola, detectado, neste estudo, foi semelhante aos valores encontrados na literatura (BRAGA et al., 2012), para a farinha do resíduo da acerola verde $(2231 \mathrm{mg} / 100 \mathrm{~g})$ e madura (2571 mg/100g), obtida por secagem a $65^{\circ} \mathrm{C}$. Os resultados deste estudo também se assemelham com os de pesquisas (BORGES, 2011), para bagaço em resíduo da acerola (2748,03 mg/100g), desidratado em leito em jorro. O resíduo desidratado da acerola é uma fonte considerável dessa vitamina, apresentando como potencial no enriquecimento de produtos alimentícios no uso da alimentação humana (BRAGA et al., 2012), já que a necessidade de ingestão diária recomendada (IDR) de um adulto é $60 \mathrm{mg}$ de vitamina $\mathrm{C}$, conforme preconiza Portaria $n^{\circ} 27$, de 13 de janeiro de 1998 (BRASIL, 1998).

O resíduo em pó da manga exibiu uma quantidade significativa de ácido ascórbico, resultado superior ao encontrado na literatura (ARAÚJO et al., 2009) (127,36 $\mathrm{mg} / 100 \mathrm{~g}$ ) para resíduo de manga espada, desidratado a $40^{\circ} \mathrm{C}$. $\mathrm{O}$ teor de ácido ascórbico encontrado para o resíduo da goiaba foi superior ao encontrado para o resíduo desidratado a $70^{\circ} \mathrm{C}$ (47,58 mg/100g), em secador convectivo de bandejas, com duração de 510 minutos (MORAES et al., 2014). A vitamina C sofre perdas durante o processo de secagem, por ser um componente termolábil (CELESTINO, 2010).

\section{CONCLUSÕES}

A secagem convectiva a $55^{\circ} \mathrm{C} / 48 \mathrm{~h}$ é favorável para obtenção de resíduos agroindustriais desidratados com qualidade para consumo, uma vez que esse método de desidratação preserva as propriedades nutricionais e funcionais dos resíduos desidratados de manga, goiaba e acerola, tornando-os microbiologicamente estáveis.

É viável a utilização tecnológica dos resíduos das frutas tropicais, manga, goiaba e acerola, para enriquecimento de produtos alimentícios, que, além de conferirem valor agregado ao produto final, podem ainda contribuir para o aproveitamento de resíduos, diminuindo o desperdício.

\section{REFERÊNCIAS}

ABUD, A. K. de. S.; NARAIN, N. Incorporação da farinha de resíduo do processamento de polpa de fruta em biscoitos: uma alternativa de combate ao desperdício. Brazilian Journal of Food Technology, Campinas/SP, v. 12, n. 4, p. 257-265, 2009.

AGUIAR, T. M.; RODRIGUES, F. S.; SANTOS, E. R.; SABAA-SRUR, A. U. O. Caracterização química e avaliação do valor nutritivo de sementes de acerola. Nutrire: Revista da Sociedade Brasileira de Alimentação e Nutrição, São Paulo/SP, v. 35, n. 2, p. 91-102, 2010.

AMBRÓSIO, C. L. B.; CAMPOS, F. A. C. S.; FARO, Z. P. Carotenoides como alternativa contra a hipovitaminose A. Revista de Nutrição, Campinas/SP, v.19, n.2, p. 233-243, 2006.

AQUINO, A. C. M. de. S.; MOES, R. S.; LEAO, K. M. M.; FIGUEIREDO, A. V. D.; CASTRO, A. A. Avaliação físicoquímica e aceitação sensorial de biscoitos tipo cookies elaborados com farinha de resíduos de acerola. Revista do Instituto Adolfo Lutz, São Paulo, v. 69, n.3, p. 379-86, 2010.

ARAÚJO, C. R. de.; MELO, E. de. A.; LIMA, V. L. A. G. de.; MACIEL, M. I. S. Resíduo agroindustrial de três variedades de mangas: Teor de fitoquímicos e ação antioxidante. In: IX JEPEX- Jornada de Ensino, Pesquisa e Extensão, 2009, Pernambuco. Anais... Pernambuco: Universidade Federal Rural de Pernambuco, 2009. 
ARAÚJO, K. L. G. V.; MAGNANI, M.; NASCIMENTO, J. A.; SOUSA, A. L.; EPAMINONDAS, P. S.; SOUZA, A. L.; QUEIROZ, N.; SOUZA, A. G. Antioxidant Activity of CoProducts from Guava, Mango and Barbados Cherry Produced in the Brazilian Northeast. Molecules, v.19, p. 3110-3119; doi: 10.3390/molecules19033110, 2014. ISSN 1420-3049.

ARAÚJO, L. M. Polpa de Jambolão (Syzygium cumini) desidratada por liofilização e secagem em leito de jorro: Caracterização físico-química e funcional e impacto da secagem. 2014. 111 f. Dissertação (Mestrado em Engenharia Química) - Universidade Federal do Rio Grande do Norte, Natal/RN. 2014.

ARBOS, K. A.; STEVANI, P. C.; CASTANHA, R. F. Atividade antimicrobiana, antioxidante e teor de compostos fenólicos em casca e amêndoa de frutas de manga. Revista Ceres, Viçosa/MG, v.60, n.2, p.161-165, 2013.

BEZERRA, T. S. Comportamento higroscópico de pós de diferentes variedades de manga (Mangifera indica L.) Fortaleza. 2009. 101 f. Dissertação (Mestrado de Tecnologia de Alimentos) - Universidade Federal do Ceara, Fortaleza. 2009.

BORGES, K. C. Estudo das características físico-químicas e funcionalidade de bagaços de frutas tropicais desidratados em leito de jorro. 2011. 138 f. Dissertação (Mestrado em Engenharia Química) - Universidade Federal do Rio Grande do Norte, Natal/ RN. 2011.

BRAGA, A. C.; LIMA, M. dos. S.; AZEVEDO, L. C. de.; RAMOS, M. E. C.Obtenção e caracterização de farinha do resíduo gerado no processo industrial de suco de Malpighia punicifolia. Revista Semiárido de Visu, Pernambuco, v.2, n.1, p.176-183, 2012.

BRAND-WILLIAMS, W.; CUVELIER, M. E.; BERSET, C. Use of a free radical method to evaluate antioxidant activity. LWT- Food Science and Technology, v.28, n.1, p.25-30, 1995.

BRASIL. Análises Físico-Químicas de Bebidas e Vinagres BEB. Método para determinação de ácido ascórbico. Lanagro- SP. 2013.

BRASIL. ANVISA- Agência Nacional de Vigilância Sanitária. Portaria $\mathrm{n}^{\circ}$ 27, de 13 de janeiro de 1998. Regulamento Técnico referente à Informação Nutricional Complementar (declarações relacionadas ao conteúdo de nutrientes). Diário Oficial da República Federativa do Brasil, Poder Executivo, Brasília, 16 dezembro de 1998.

BRASIL. ANVISA- Agência Nacional de Vigilância Sanitária. Resolução RDC no 12, de 02 de janeiro de 2001. Regulamento Técnico sobre padrões microbiológicos para alimentos. Diário Oficial da República Federativa do Brasil, Poder Executivo, Brasília, 10 de janeiro de 2001.

BRASIL. ANVISA- Agência Nacional de Vigilância Sanitária. Resolução RDC n ${ }^{\circ} 272$, de 22 de setembro de 2005. Regulamento Técnico para produtos de vegetais, produtos de frutas e cogumelos comestíveis. Diário Oficial da República Federativa do Brasil, Poder Executivo, Brasília, 23 de setembro de 2005 .

CAETANO, P. K.; DAIUTO, E. R.; VIEITES, R. L. Caracterização físico-química e avaliação energética de geleia elaborada em diferentes tipos de tachos com polpa e suco de acerola. Revista Energia na Agricultura, Botucatu, v. 26, n.2, p.103-118.2011. ISSN 1808-8759.

CELESTINO, S. M. Princípios de Secagem de alimentos. Planaltina, DF: Embrapa Cerrados, 2010.

CRUZ, S. K. da.; MEIRELES, G. C.; DUARTE, L. S.; SILVEIRA, C. M. da.; MOURA, C. M. Secagem de bagaço de oliveira: Influência da velocidade do ar na concentração de compostos bioativos. In: $8^{\circ}$ Salão Internacional de Ensino, Pesquisa e Extensão, 8.,2014, Rio Grande do Sul. Anais... Rio Grande do Sul: Universidade Federal do Pampa, 2014.

CRUZ, W. F. da. Obtenção da polpa de goiaba (Psidium guajava L.) em pó pelo método de secagem em camada de espuma. 2013. 78 f. Dissertação (Mestrado em Ciência e Tecnologia de Alimentos) - Universidade Federal de Viçosa, Viçosa/MG. 2013.

DAMIANI, C.; BOAS, E. V. B. V.; JUNIOR, M. S. S.; CALIARI, M.; PAUKA, M. L.; PEREIRA, D. E. P.; SILVA, A. G. M. Análise física, sensorial e microbiológica de geleias de manga formuladas com diferentes níveis de cascas em substituição à polpa. Ciência Rural, Santa Maria, v.38, n.5, p.1418-1423, 2008.

DUARTE-ALMEIDA, J. M.; SANTOS, R. J. dos.; GENOVESE, M. I.; LAJOLO, F. M. Avaliação da atividade antioxidante utilizando sistema $\beta$-caroteno/ácido linoléico e método de sequestro de radicais DPPH .Ciência e Tecnologia de Alimentos, Campinas, v.26, n.2, p.446-452, 2006.

DUARTE, M. E. M.; MATA, M. E. R. M.; AGRA, N. G. Comparação entre as características físico-químicas da manga liofilizada e a manga-passa. Revista Brasileira de Produtos Agroindustriais, Campina Grande, v.8, n.2, p.127-134, 2006.

FARAONI, A. S. Desenvolvimento de sucos mistos de frutas tropicais adicionados de luteína e epigalocate quinagalato. 2009.151 f. Tese (Doutorado em ciência e tecnologia de alimentos) - Universidade Federal de Viçosa, Viçosa/MG. 2009.

FELLOWS, P. J. Tecnologia do Processamento de Alimentos: Princípios e Práticas. 2 ed. Porto Alegre: Artmed, 2006. 602 p.

FREITAS, C. A. S.; MAIA, G. A.; COSTA, J. M. C.; FIGUEIREDO, R. W.; SOUSA, H. M. Acerola: Produção, composição, aspectos nutricionais e produtos. Revista Brasileira de Agrociência, Pelotas, v.12, n.4, p.395-400, 2006.

FREIRE, M. T. de. A.; PETRUS, R. R.; HASHIDA, J. C.; FAVARO-TRINDADE, C. S. Avaliação física, química e sensorial de doce cremoso de goiaba acondicionado em 
bisnaga plástica. Brazilian Journal of Food Technology, Campinas/SP,v. 12, n. 3, p. 172-180, 2009.

GAVA, A. J.; SILVA, C. A. B. da.; FRIAS, J. R. G. Tecnologia de Alimentos: Princípios e Aplicações. São Paulo: Nobel, 2008. 512 p.

HAIDA, K. S.; HAAS, J.; MELLO, S. A.; HAIDA, K. S.; ABRÃO, R. M.; SAHD, R. Compostos Fenólicos e Atividade Antioxidante de Goiaba (Psidium guajava L.) fresca e congelada. Revista Fitos, Rio de Janeiro, v.9, n.1, p.1-72, 2015 .

INFANTE, J.; SELANI, M. M.; TOLEDO, N. M. V. de.; SILVEIRA-DINIZ, M. F.; ALENCAR, S. M. de.; SPOTO, M. H. F.Atividade antioxidante de resíduos agroindustriais de frutas tropicais. Alimentação e Nutrição, Araraquara v. 24, n. 1, p. 87-91, 2013.

INSTITUTO ADOLFO LUTZ. Normas analíticas do Instituto Adolfo Lutz: métodos químicos e físicos para análises de alimentos. 1. ed. Digital. São Paulo: IAL, 2008.1020 p.

JORGE, A. Avaliação comparativa entre processos de secagem na produção de tomate em pó. 2014. 68f. Dissertação (Mestrado em Engenharia de Produção) Universidade Tecnológica Federal do Paraná, Pronta Grossa. 2014.

JÚNIOR, J. E. L.; COSTA, J. M. C. da.; NEIVA, J. N. M.; RODRIGUEZ, N. M. Caracterização físico-química de subprodutos obtidos do processamento de frutas tropicais visando seu aproveitamento na alimentação animal. Revista Ciência Agronômica, Fortaleza/CE, v.37, n.1, p.70-76, 2006.

KIM, D. O.; JEONG, S. W.; LEE, C. Y. Antioxidant capacity of phenolic phytochemicals from various cultivars of plums. Food Chemistry, Kidlington, v.81, n.1, p.321-326, 2003.

LIMA, C. E.; SOUSA, M. C.; PENHA, M. F. A. Aproveitamento integral da acerola na formulação de bolos. In: XXV Congresso Brasileiro de Ciência e Tecnologia de Alimentos, Alimentação: A árvore que Sustenta a Vida, 15., 2016, Gramado/RS. Anais...Gramado: FAURGS, 2016.

MARTIM, N. S. P. P. Estudo das características de processamento da manga (Mangifera indica L.) variedade Tommy atkins desidratada. 2006. 76 f. Dissertação (Mestrado em Tecnologia de Alimentos) - Universidade Federal do Paraná- UFPR, Curitiba/PR. 2006.

MATOS, A. P. de. Manga produção: Aspectos técnicos. Brasília: Embrapa, Comunicação para Transferência de Tecnologia, 2000. p.1-63.

MEIRELES, A. M. de.; SOUZA, L. M. de. Desenvolvimento e caracterização físico-química, microbiológica, sensorial de produtos à base de manga. 2015. 81 f. Trabalho de Conclusão de Curso (Tecnologia em Alimentos) - Universidade Tecnológica Federal do Paraná Departamento de Ensino e Pesquisa, Medianeira. 2015.
MELO, P. S. Composição química e atividade biológica de resíduos agroindustriais. 2010. 100 f. Dissertação (Mestrado em Ciência e Tecnologia de Alimentos) - Universidade de São Paulo, Piracicaba. 2010.

MORAES, F. P.; SILVA, E. S. da.; ROCHA, P. M.; SILVA, A. S. da.; CORREIA, R. T. P. Avaliação dos compostos bioativos presentes no resíduo de goiaba vermelha (Psidium guajava L.) desidratada. In: XX Congresso Brasileiro de Engenharia Química, 10., 2014, Florianópolis/SC.Anais...Florianópolis: COBEQ, 2014.

MORENO, J. de. S. Obtenção, caracterização e aplicação de farinha de resíduos de frutas em cookies. 2016. $81 \mathrm{f}$. Dissertação (Mestrado em Ciência de Alimentos) Universidade Estadual do Sudoeste da Bahia, Itapetinga/Bahia. 2016.

MUNIZ, C. E. S.; SANTIAGO, A. M.; GALDINO, P. O.; BRITO, K. D.; ALMEIDAS, M. M.; NÓBREGA, D. M. Aproveitamento integral da acerola na formulação de bolos. In: XXV Congresso Brasileiro de Ciência e Tecnologia de Alimentos, Alimentação: A árvore que sustenta a vida, 15.,2016, Gramado/RS. Anais...Gramado: FAURGS, 2016.

NAGATA, M.; YAMASHITA, I. Simple method for simultaneous determination of chlorophyll and carotenoids in tomato fruit.J. Japan. Soc. Food Science and Technology, Nippon Shokuhin Kogyo Gakkaishi, v. 39, n. 10, p. 925-928, 1992.

NÓBREGA, E. M. M. de. A. Secagem do resíduo de acerola (Malphigia emarginata DC.): Estudo do processo e avaliação do impacto sobre o produto final. 2012. 102 f. Dissertação (Mestrado em Engenharia Química) - Universidade Federal do Rio Grande do Norte, Natal/RN. 2012.

NÓBREGA, E. M.; OLIVEIRA, E. L.; GENOVESE, M. I.; CORREIA, R. T. P. The impact of hot air drying on the physical-chemical characteristics, bioactive Compounds and antioxidant activity of acerola (Malphigia emarginata) residue. Journal of Food Processing and Preservation. Doi: 10.1111/jfpp. 12213.2014.ISSN 1745-4549.

NOBRE, V. N.; SOUSA, M. S.; MARTINS, R. Elaboração e aceitação sensorial de massa salgada com farinha da casca de manga e trigo. Faculdade de Tecnologia CENTEC - Sertão Central, Ceará, 2011. Disponível em: <http://tecnologiaemalimentos.blogspot.com.br/2011/04/farinha-alternativa- emmassa- salgada-da.htmL>. Acesso em: 26 set. 2017.

NUNES, J. S.; SILVA, F. B. da.; GOMES, J. P.; SILVA, W. P. da. Caracterização físico-química de farinha resíduo de polpa de acerola. In: CONTECC-Congresso Técnico Científico da Engenharia e da Agronomia Contecc, 2015, Ceará/Fortaleza. Anais... Ceará/Fortaleza: Centro de eventos do Ceará, 2015.

OLIVEIRA, J. B. de. Caracterização química, bioquímica e valor calórico de resíduos desidratados da indústria frutícola de maracujá (Passiflora edulis $f$. flavicarpa) e manga (Mangifera indica L). 2013. 100 f. Dissertação (Mestrado em 
Tecnologia em Alimentos) -Universidade Estadual do Sudoeste da Bahia, Itapetinga/BA. 2013.

OLIVEIRA, L. M. N. Quantificação de rutina, atividades antioxidante e antimicrobiana de extratos de polpas e subprodutos de frutas tropicais. 2014. 87 f. Dissertação (Mestrado em Ciência e Tecnologia de Alimentos) Universidade Federal do Ceará, Fortaleza. 2014.

PEREIRA, P. A. P. Elaboração de geléia utilizando resíduo do processamento de goiaba (Psidium guajava L.). 2009. 118 f. Dissertação (Mestrado em Ciência dos Alimentos) Universidade Federal de Lavras, Lavras/MG. 2009.

PRADO, A. Composição fenólica e atividade antioxidante de frutas tropicais. 2009. 106 f. Dissertação (Mestrado em Ciência e Tecnologia de Alimentos) - Universidade de São Paulo, Piracicaba. 2009.

REINOSO, A. C. L.; CARNELOSSI, M. A. G.; BERY, C. C. de. S.; SOUZA, R. R. de.; CONCEIÇÃO, A. M. da.; OLIVEIRA, J. K. de. Efeitos das temperaturas na conservação dos minerais em farinhas de cascas de mangas. Interfaces Científicas - Saúde e Ambiente, Aracaju, v.5, n.2, p. $25-32,2017$.

RIBEIRO, E. P.; SERAVALli, E. A. G. Química de Alimentos. 2 ed. São Paulo: Blucher, 2007.184 p.

SANTOS, A. C. dos. Avaliação do uso da farinha de casca da manga Tommy atkins na reologia da farinha de trigo e na aceitabilidade do pão de forma. 2013. 50 f. Trabalho de conclusão de curso (Tecnologia em Alimentos) Universidade Tecnológica Federal do Paraná, Campo Mourão. 2013.

SANTOS, C. de. N. P. dos. Elaboração de um estruturado de polpa de manga (Mangifera indica L. cv Tommy atkins) parcialmente desidratada por osmose.2003. 97 f. Dissertação (Mestrado em Tecnologia em Alimentos) - Universidade Federal de Campinas, Campinas/SP. 2003.

SANTOS, T. S. Extração de carotenoides totais e $\beta$-caroteno por ultrassom no resíduo de indústria de polpa de goiaba (Psidium guajava L.). 2013. 85 f. Dissertação (Mestrado em Química) - Universidade Federal de Sergipe, São Cristóvão/SE. 2013.

SILVA, A. C. da.; PAUlA, S. C. S. E. de.; BERTOQUE, A. K. C.; REBEllo, L. P. G.; SILVA, W. A. da. Aproveitamento do co-produto do processamento de goiaba (Psidium guajava): caracterização físico-química da farinha e seu potencial no desenvolvimento de novos produtos. In: XXV Congresso Brasileiro de Ciência e Tecnologia em Alimentos, Alimentação: A Árvore que Sustenta a Vida, 15.,2016, Gramado/RS. Anais...Gramado:FAURGS, 2016.

SILVA, D. A. da. Utilização da farinha de resíduos de acerola e umbu cajá na produção de bolo tipo cupcake. 2017. 89 f. Tese (Doutorado em Desenvolvimento e Meio Ambiente) Universidade Federal de Sergipe, São Cristóvão/SE. 2017.
SILVA, D. S. Estabilidade do suco tropical de goiaba (Psidium guajava L.) não adoçado obtido pelos processos de enchimento à quente e asséptico.2007. 100 f. Dissertação (Mestrado em Tecnologia de Alimentos) - Universidade Federal do Ceará, Fortaleza. 2007.

SILVA, I. F. B. da.; SOUSA, B. A. de. A.; BESERRA, A.; SILVA, W. A.; MEDEIROS, G. C. de. A. Elaboração de biscoitos tipo cookies com farinha de resíduos do processamento de polpa de acerola. In: Encontro Nacional de Educação, Ciência e Tecnologia, 15., 2012, João Pessoa. Anais... João Pessoa: UEPB, 2012.

SOBRINHO, I. S. B. Propriedades nutricionais e funcionais de resíduos de abacaxi, acerola e cajá oriundos da indústria produtora de polpas. 2014. 166 f. Dissertação (Mestrado em Ciências Ambientais) - Universidade Estadual do Sudoeste da Bahia, Itapetinga/BA. 2014.

SOUSA, B. A. de. A. "Funcionalidade dos extratos fenólicos obtidos pelo cultivo semissólido de resíduos de abacaxi (Ananas comosus L.) e goiaba (Psidium guajava L.)". 2009. 118 f. Dissertação (Mestrado em Engenharia Química) Universidade Federal do Rio Grande do Norte, Natal/RN. 2009.

SOUZA, J. C. B.; COSTA, M. R.; RENSIS, C. M. V. B.; SIVIERI, K. Sorvete: Composição, processamento e viabilidade da adição de probiótico. Alimentos e Nutrição, Araraquara, v.21, n.1, p.155-165, 2010.

VEGA-GÁLVEZ, A.; SCALA, K. DI.; RODRÍGUEZ, K.; LEMUS-MONDACA, R.; MIRANDA, M.; LÓPEZ, J.; PEREZ-WON, M. Effect of air-drying temperature on physicchemical properties, antioxidant capacity, colour and total phenolic content of red pepper (Capsicum annuum, L. var. Hungarian). Journal of Agricultural and Food Chemistry, Washington, v. 117, n.4, p.647-653, 2009.

VIEIRA, P. A. F. Caracterização dos resíduos da manga (Mangifera indica L.) e efeitos sobre o desempenho e os parâmetros bioquímicos em frango de corte. 2007. 92 f. Dissertação (Mestrado em Bioquímica Agrícola) Universidade Federal de Viçosa, Viçosa/Minas Gerais. 2007. 